\title{
Sixty-nine years after surviving the polio epidemic
}

\author{
Barry J. McMahon, Sue Dojeiji MD MEd, Rene A. Leiva MD, Joan M. Fisher BN MEd
}

Cite as: CMAJ 2021 December 20;193:E1915-7. doi: 10.1503/cmaj.210985

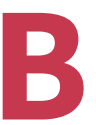

arry McMahon, a 72-year-old retired film and video producer, received a diagnosis of acute paralytic polio in 1951 when he was 3 years old. His respiratory and bilateral arm and leg muscles were affected, but he did not require an iron lung. He spent months in isolation in hospital, followed by several months in convalescence and rehabilitation. His first sign of recovery was movement in his left toe.

Barry was left with persistent weakness in his arms and legs, particularly on his right side. He learned to walk without gait aids, but required a knee-ankle-foot orthosis to support his right leg, which he used for 8 years. He had a right ankle fusion and tendon transfers to support his right foot and ankle, and to allow safe ambulation. His weakness never improved, but he learned to accommodate it. He was able to work, raised a family and pursued many interests.

A major fall in the 1980 s caused Barry to fracture his femur. In 1990 , he started to use a scooter to prevent further falls and to manage reduced muscle endurance.

In 1996, with no specific injury or illness, Barry developed a rapid onset of increasing fatigue, reduced muscle endurance with new weakness, and generalized and intractable pain. Given his history of polio, and with no other causes identified, a physiatrist diagnosed postpolio syndrome. ${ }^{1}$ Because of ongoing symptoms, Barry applied for long-term disability in 1996. Despite his personal challenges, he has continued to volunteer with various community charitable organizations.

Several factors make Barry's postpolio syndrome-related symptoms difficult to manage. Identifying health care providers who are knowledgeable about the late effects of polio and how to address them without provoking further or new symptoms is one challenge. Of all the symptoms, pain has been the most challenging to control. Barry's pain is multifactorial; it is constant, generalized and varies in intensity according to activity, which is common in postpolio syndrome.

\section{Patient's perspective}

There are about 31000 aging polio survivors in Canada, and fewer than half have symptoms of postpolio syndrome. We are not a large cohort and are left in a bit of a health care conundrum.

I have used a variety of ever-evolving assistive devices, and my home incorporates Universal Design Principles. ${ }^{2}$ However,

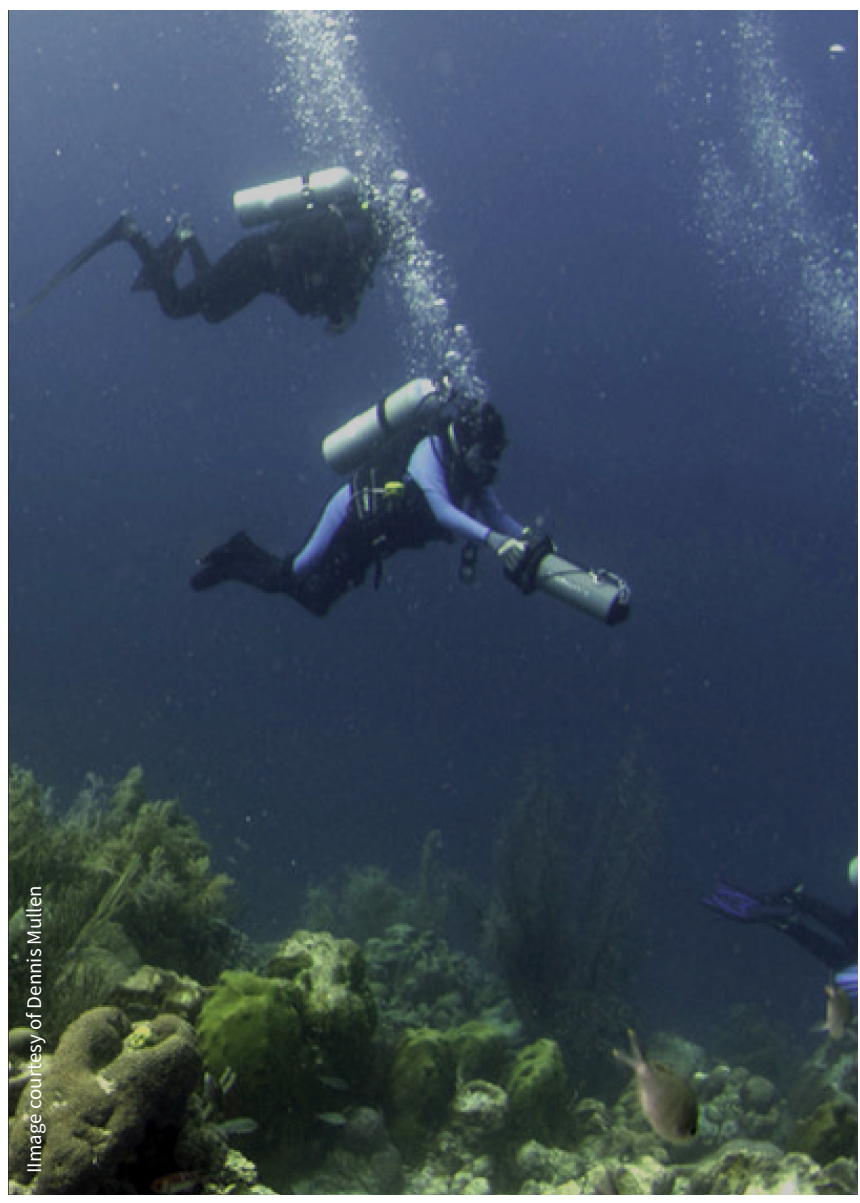

"Finless" scuba diver is Barry McMahon using a diver propulsion vehicle.

the best intervention has been the help I get from my soulmate, my daughters and the personal support workers provided to me by my local community agency.

Apart from a few minor studies conducted over the past few decades, ${ }^{3}$ little clinical research is being done on postpolio syndrome. I presume this is because our cohort is small and gradually dying off, and therefore the profit-generating incentives for the pharmaceutical industry are negligible.

So, without much guidance from clinical studies, my doctors do their best based on their judgment and their experience treating people with polio and other conditions. It's a matter of "make 
it up as we go." For instance, I was prescribed methylphenidate to manage fatigue. After a few years, I stopped because I started to question its effect on my weakness and pain symptoms. When I read up on it, I found that it had limited benefit for some people with chronic fatigue syndrome, ${ }^{4}$ but could find no evidence of its efficacy for postpolio syndrome.

It seems that polio affects survivors differently and, therefore, managing symptoms is as individualized as can be imagined. Online groups for polio survivors provide ample evidence that little is truly known, though many theories exist. Because quality of life is what it is all about, the online discussions cover lots of ideas for symptom management, but it is easy to see that polio survivors need informed physician guidance.

About 14 years ago, I was fortunate to discover that I could scuba dive with the help of a scuba instructor and his team who specialized in instructing people with disabilities. In winter, I dive on the reefs off the Dutch Antilles island of Bonaire. During the summer, the shipwrecks in the St. Lawrence River provide a lot of adventure. After more than 260 recorded dives, I am convinced that I have gained therapeutic benefits and hope to continue as long as possible.

In general, polio survivors are fiercely independent, ${ }^{5}$ and we tend to be quite capable of effectively directing our health care concerns. Those of us with extensive mobility limitations are taking advantage of the emergence of telemedicine (thanks in part to the pandemic), especially during winter. I feel more connected to my health care professionals and hope the trend continues. Face-to-face meetings are obviously still necessary for physical examinations and surgeries.

Many factors related to my postpolio syndrome are still mysterious. How do I know if my other symptoms - intolerance to cold, sensitivity to medications, swallowing issues, weight gain and edema - are part of the postpolio syndrome or have another underlying cause? How is the natural aging process influenced by postpolio syndrome?

I have always believed that carefully balancing physical, mental and spiritual health is the goal. When that equilibrium is attained, my resilience to meet the constantly changing pressures of life is strengthened. - Barry J. McMahon

\section{Best friend's perspective}

Barry and I met 4 years ago, 4 and 3 years after losing our respective spouses.

I was aware of polio, having experienced school closures during the 1959 epidemic in Newfoundland as a child. My first job in 1968 was at the Children's Rehab Centre in St. John's, where some of the patients were learning to adapt to the effects of having had polio 9 years earlier.

I had not heard, however, of postpolio syndrome until I met Barry. Barry is fiercely independent. I was impressed that Barry, although restricted to a power wheelchair, was able to drive, scuba dive, cook a wonderful meal, provide after-school care for 5 of his grandchildren and live independently, with minimal support from personal support workers for morning hygiene and dressing.
Barry never complains of pain but, when asked, confirms it is always present to some extent. He also suffers from muscle spasms and cramps, sensitivity to cold and lower extremity edema.

Barry copes with his mobility limitations and fear of falling by using rigorous routines for standing, transferring to and from his wheelchair, dressing and preparing meals. Over the past 4 years, I have managed to cajole him into wearing compression stockings and using alternating pressure boots while sitting. Although these have increased his dependence on others to put on and take off the stockings, they have relieved edema and discomfort in his lower extremities.

Massage helped with Barry's cramping thigh muscles, until the occupational therapist designed side supports at the edges of his wheelchair seat to relieve some of the adduction concerns.

Barry is continually analyzing his symptoms and proactively solving the problems as best he can. Some of his abilities have slowly waned. In the past 6 months, he no longer feels confident in his driving ability as the responsiveness of his dominant left leg and foot has reduced. Perhaps postpolio syndrome is accelerating the normal slowing of responses we all experience as we age.

I am doing my best to support Barry's wish to remain independent. Even though I am a retired health professional, it was not until I became personally involved that I became conscious of how staff in airports, shops, hotels and so on tend to talk to me, rather than to Barry in his wheelchair. I also note that most people do not even think about accessibility issues until it affects them or a loved one. - Joan M. Fisher

\section{Physiatrist's perspective}

I met Barry in 2001 after his previous physiatrist retired. For decades, he had been followed in a neuromuscular rehabilitation clinic for his postpolio syndrome. We focus our clinic visits on several goals, including wheelchair comfort, safe transfers, energy conservation and pain management. ${ }^{6}$ Barry comes to all his clinic visits with a list of updates and questions about issues that he has identified. These are usually quickly followed by a plan he wants to discuss. For example, at one visit, Barry described a precarious transfer after a bout of illness. After I screened for other functional issues and performed a targeted neuromusculoskeletal examination, we reviewed various management options, like a Super Pole for bed transfers. Barry initially proclaimed, "I don't think that I need that yet." । respected his perspective, and eventually Barry became open to trialing aids. Adding assistive aids improved Barry's function and quality of life.

Pain management is an ongoing issue, particularly as Barry gets older. I have focused on exploring nonmedical strategies. Over the years, we have tried various modalities, stretching programs, water-based therapy and massage therapy. We reviewed his power wheelchair to ensure maximum comfort. He kept an activity log and mapped tasks to his pain perception to try to identify contributing factors. We reviewed energy conservation and pacing strategies. At one point, Barry wondered about using medicinal marijuana. A literature review 
yielded limited anecdotal guidance for people with postpolio syndrome. I suggested working with a medical marijuana practitioner, and we discussed specific outcome metrics Barry could use to gauge its effect. He is working through that trial.

Barry began scuba diving with an instructor specializing in diving for people with disabilities. Having no medical contraindications to diving, Barry literally dove in. He reported less pain, especially on dive days. We discussed the factors that might be contributing to this, such as distraction and positive attitude from a new and challenging activity, movement in a weightless environment and enhanced fitness. Unfortunately, the COVID-19 pandemic has curtailed this vital activity substantially.

Additional challenges we have encountered include accessing funding for equipment and therapies. Specialized outpatient and community services are vulnerable to provincial cutbacks. For example, there is a dearth of outpatient clinical psychology to assist individuals who are struggling to cope with the acute, chronic and progressive phases of their disability. Many times, Barry has self-funded aids and services. The pandemic has amplified those challenges, with increased wait times for essential in-home services, such as access to the services of personal support workers. - Sue Dojeiji

\section{Family physician's perspective}

I met Barry 10 years ago, when he and his late spouse became my patients. He was already under the care of his physiatrist, so I viewed this as an opportunity to help as a skilled clinician and resource. I have come to appreciate the impact of his postpolio syndrome. The constellation of pain, weakness, fatigue and other symptoms has presented a challenge as he ages, and resources and support are limited. Credit to him, Barry possesses a strong will for holistic self-health promotion, and has good social support and a committed medical team around him.

We work together to try to find solutions; we have considered, trialed and discarded many. For instance, at one point we entertained the use of medical marijuana for his pain. I provided Barry with my opinion about the evidence (or lack thereof) for its use. I believe that it is our long-standing patient-doctor relationship that has allowed us the freedom to explore even nontraditional approaches.

I have met Barry's family. It is crucial that I am aware of the role they, his friends and caregivers play in his illness and care, and I must be ready to collaborate with them to address any concerns. Besides Barry, they are often the first to note any deterioration or new needs. Barry has a strong relationship with his daughters, and they openly discuss all issues related to his wellbeing. They even suggest investigations; they once requested testing for celiac disease because one of them had the disorder.
His daughters consult with each other if there is a change in his general health, and they made sure he has a power of attorney for health care.

As Barry ages, I hope to remain one of his health advocates to make sure his care needs are addressed, especially with proper community support and appropriate medical interventions. - Rene A. Leiva

\section{References}

1. Farbu E, Gilhus NE, Barnes MP, et al. EFNS guideline on diagnosis and management of post-polio syndrome. Report of an EFNS task force. Eur J Neurol 2006;13:795-801.

2. Connell BR, Jones M, Mace R, et al. 7 guiding principles. Dublin: Universal Design Network of Canada; 2020. Available: https://universaldesign.ie/What-is -Universal-Design/The-7-Principles/ (accessed 2021 Aug. 27).

3. Koopman FS, Beelen A, Gilhus NE, et al. Treatment for post-polio syndrome. Cochrane Database Syst Rev 2015;(5):CD007818.

4. Blockmans D, Persoons P, Van Hoodenhove B, et al. Does methylphenidate reduce the symptoms of chronic fatigue syndrome? Am J Med 2006;119:167.e23-30.

5. Bruno R. The Type A polio survivor. International Centre for Polio Education; 2018. Available: type_a_polio_survivors.pdf (accessed 2021 Oct. 21).

6. What is a Physiatrist? Kingston (ON): Canadian Association of Physical Medicine and Rehabilitation; 2018. Available: https://www.capmr.ca/about-capmr/ what-is-a-physiatrist (accessed 2021 Aug. 27)

\section{Competing interests: None declared.}

This article has been peer reviewed.

Affiliations: Patient (McMahon), Ottawa, Ont.; Ottawa Hospital Rehabilitation Centre (Dojeiji), Ottawa, Ont.; Bruyère Continuing Care (Leiva); Department of Family Medicine (Dojeiji, Leiva), University of Ottawa, Ottawa, Ont.; Friend (Fisher), Ottawa, Ont.

Content licence: This is an Open Access article distributed in accordance with the terms of the Creative Commons Attribution (CC BY-NCND 4.0) licence, which permits use, distribution and reproduction in any medium, provided that the original publication is properly cited, the use is noncommercial (i.e., research or educational use), and no modifications or adaptations are made. See: https://creativecommons.org/ licenses/by-nc-nd/4.0/

Correspondence to: cmajgroup@cmaj.ca

360 Cases highlight the interpersonal and systemic aspects of health care that are seldom discussed in other Practice articles. Each comprises a brief case summary, followed by personal reflections from 2-4 people involved in the clinical encounter. One author must be a patient, family member or caregiver; the other authors may be anyone involved in the encounter (i.e, physicians, nurses, social workers, dietitians, etc.). For more information, see https://www.cmaj.ca/submission-guidelines or contact Victoria Saigle (Victoria.saigle@cmaj.ca). 